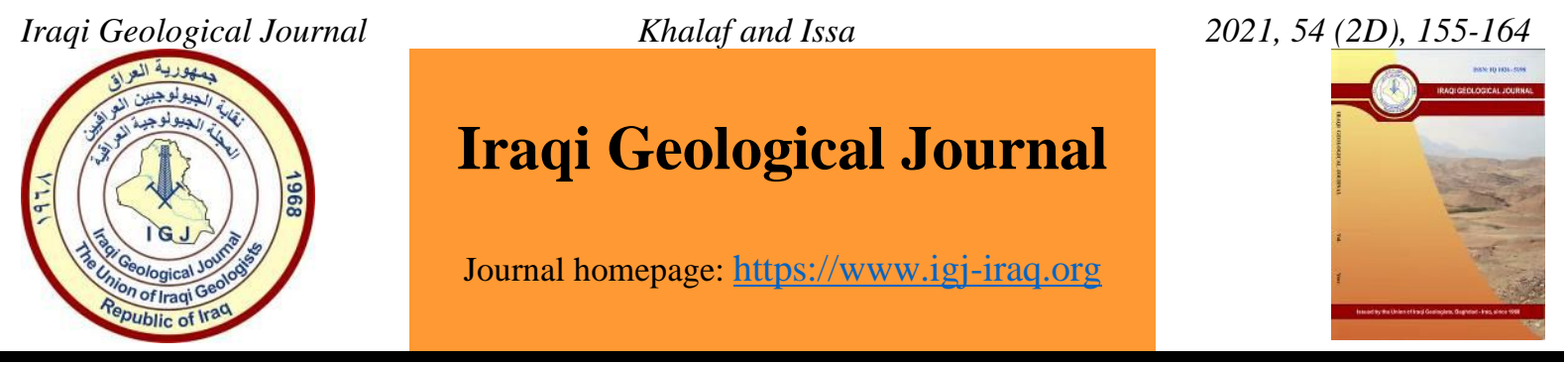

\title{
Study of the Relationship between some Physical Properties of Selected Soils in Babylon, Central Iraq
}

\author{
Muhsen O. Khalaf ${ }^{1, *}$ and Bilal M.A. Issa ${ }^{1}$ \\ 1 Department of Applied Geology, College of Science, University of Babylon, Babylon, Iraq \\ * Correspondence: Sci.muhsen.khalif.lec@uobabylon.edu.iq
}

Received: 14 June 2021; Accepted: 14 July 2021; Published: 31 October 2021

\begin{abstract}
The research is based on five selected soil sites in Babylon, Iraq, and aims to find the relationship between the physical properties of the soil. Where five samples were taken at different depths with a description of the soil for them in the fieldwork stage. As for the laboratory investigations phase, it included exploratory grain size distribution and atterberg limits to find plasticity and inspecting the maximum dry density. It was found through these tests that the soil is clay with low plasticity, except the fourth and fifth samples, as it is silty clay with low plasticity. Soil efficiency for all samples is Inactive. The relationship between the physical properties depends on the grain size distribution characteristic, as it is a function of the rest of the properties. It was also found that the percentage of sand in clay soils increases the maximum dry density in them so that $20-30 \%$ of the form and the remainder do not exceed fine sizes (silt and clay), and with acceptable plasticity that is important in the field of using the soil for backfilling purposes under the foundations for engineering structures and roads.
\end{abstract}

Keywords: Soils; Physical properties; Grain size distribution; Atterberg limits; Maximum dry density

\section{Introduction}

Soils in Iraq differ from one place to another, whether from a geological or engineering point of view, and the reason for this is due to the way they are formed and the genetic relationship between the components of the original soil and the bedrock, in addition to the transport It is thus characterized by the phenomenon of swelling when wetting, and cracking when drying, where large voids are formed and thus affect the reduction of compressive resistance to it factors and climatic influences (Holtz and Kovacs, 1981 and Ajeet, 2015).

In general, soils in Iraq can be divided into three parts, one of which is the soil of the highlands and the western plateau in the north and west, and the other is the soil of the alluvial plain in the middle and south, and the last is the soil of the desert regions. The soils of the alluvial plain belong to the Quaternary and are mostly flooded river soils with wind deposits. (Jassim and Goff, 2006). It is known that the soil is divided into three parts according to clay soils, silty soils, and sandy soils, and each type has specific engineering properties (Arthur, 2007). Clay soils are characterized by their high plasticity and the increase in the surface area of their grains, as they consist of fine particles, and thus they need large quantities of water for their formation (Jawaid et al., 2016).

DOI: 10.46717/igj.54.2D.12Ms-2021-10-31 
It is characterized by the phenomenon of swelling when wetting and cracking when drying, where large voids are formed and thus affect the reduction of compressive resistance to it (Kalkan et al., 2020) In the case of comparison between sandy soils and the rest of the soils, sandy soils have a higher bearing capacity when constructing engineering installations on them than clay and silty ones, and fewer problems and subsidence occur in a short time that may disappear during construction (Braja and Khaled, 2018). Soils in general have physical and chemical properties that make them of specificity and us. The size distribution property is important in giving other physical properties such as plasticity, density, dryness, freshness, specific weight, and water content. (Abdulla and Majeed, 2021). As there is a close correlation between these properties. Addition of materials and their effect on soil properties and strength, (Mahendran and Vignesh, 2015) In this study, they showed the importance of finding materials instead of clay and focused on adding some secondary materials to increase cohesion strength and improved the functionality of soil properties such as using alumina, lime and herbal materials. Enhance the properties of engineering soil (Abdulla and Majeed, 2021), this study focused on alleviating the problems of soil swelling and working to enhance the physical and engineering properties of the soil by adding some secondary materials such as marble waste powder because it reduces the rate of soil swelling. In this paper, we have studied the relationship between these physical properties of soil samples of varying size distribution (Luan et al., 2021).

\section{Location of the Study Area}

The study area is located in Babylon, middle of Iraq, which is within the sedimentary plain, where they lie between longitude east 43 $59^{\prime} 54.556^{\prime \prime}-44^{\circ} 30^{\prime} 40.471^{\prime \prime}$ and latitudes north $33^{\circ} 1^{\prime} 49.827^{\prime \prime}-$ 31 ${ }^{\circ} 57^{\prime} 22.197^{\prime}$. The study area permeates the Euphrates River, where it enters the north of Babylon, and then branches into what to be known locally as Shat Al Hilla (Al-Jeafir, 2020) (Fig.1). The study area is located to the south and southwest of Baghdad, where the center of Babylon is about $80 \mathrm{~km}$ from Baghdad, the study area surrounds six Iraqi governorates, which are as follows: Baghdad, Al-Qadissiya, Al-Anbar, Karbala, Najaf, Muthanna, and Wasit (Fig. 1).

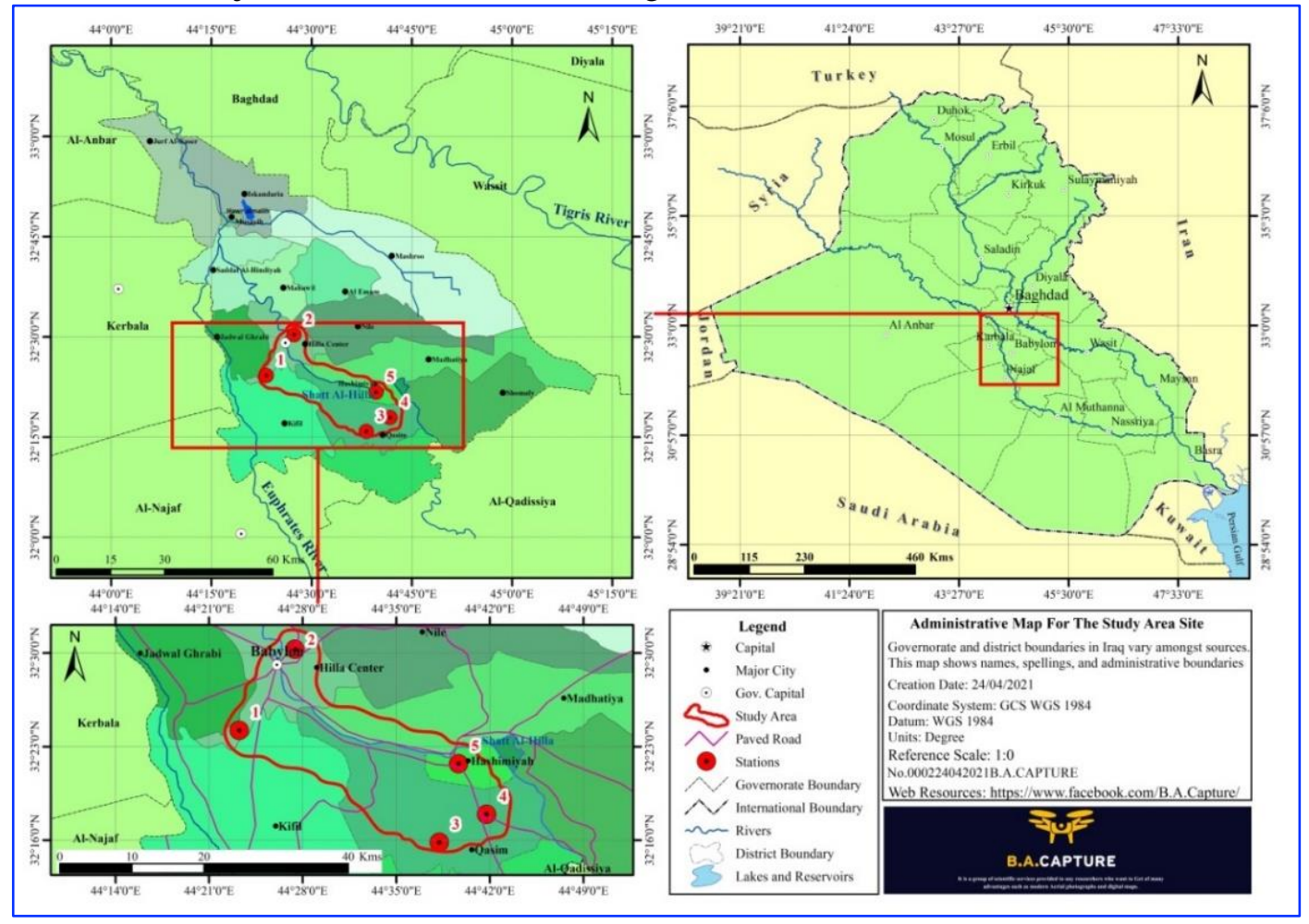

Fig. 1. Map of the study area showing samples sites (Capture, 2021) 


\section{Geology and Topography of the Study Area}

In general, the geology of the study area is not different from the geology of the sedimentary plain because it is located within it, where the sediments that cover the study area return to the era in which the rivers formed, which is the Quaternary Era. Exposure to a series of periodic precipitation and weather conditions as a result of climate changes during the Ice Age is what distinguishes this sedimentary plain (Jassim, 2006). The largest part of the research area from the geological point of view is covered by Flood Plain Deposits. The northeast, eastern and southeastern part of the study area is generally covered with aeolian deposits (Sissakian, 2012). The study area is characterized by the following deposits (Depression fill deposit, Dry marsh deposit, Inland sabkha deposit).

The surface of the study area, in general, is characterized by its flatness and its general slope from north to south, that the equal elevation line $(65 \mathrm{~m})$ above sea level passes in its northern parts in Babylon, while the equal elevation line $(25 \mathrm{~m})$ above Sea level passes through its southern parts in the Babylon.

\section{Materials and Methods}

In this section, we deal with the methods used to complete this research, whereby the available devices and techniques were used to complete the required engineering tests so that we can understand the most accurate results of the studied soil samples, which include several stages starting from the survey phase in the process of collecting information related to the geology in the study area available on the clay. In addition to preparing the site map for the five samples and starting the meticulous fieldwork stage, which consists of collecting, transporting, and preparing samples for physical and engineering tests, and indicating the extent of the relationship between these properties. The study was conducted through fieldwork, engineering tests for clayey soil, and laboratory preparation and its procedures, all of which were carried out in the laboratories of the Department of Applied Geosciences, College of the Science, University of Babylon.

\subsection{Field Work}

The field survey was conducted to choose the appropriate sites for drilling and to study the surrounding areas from the environmental fact of view, the extension of agricultural lands, irrigation projects and the extent of their accessibility, and others. The coordinates of the studied drilling sites were recorded using the GPS device in (Table 1). Drilling was provided out at all study sites with a hand drilling tool (Auger). Where this tool perforates the soil to make a hole with a diameter 4 inches and contains four iron joints, each of them is $1 \mathrm{~m}$ long, where the five sites were drilled at varying depths and randomly and this is presented in Table 1 . The soil was described in the field based on analytical and manual testing of all the samples extorted from the pits, the samples extracted from the pits were brown to yellowish-gray. Then studied soil was described after performing geotechnical investigations on it using the Unified Soil Classification System (ASTM D-2486).

Table 1.The study area's sample sites, depth, locations, and their coordinates

\begin{tabular}{|c|c|c|c|c|}
\hline Sample No. & Depth (m) & Location & \multicolumn{2}{|c|}{ The coordinates } \\
\hline & & & Latitude & Longitude \\
\hline 1 & 0.75 & $\begin{array}{c}\text { Near University of } \\
\text { Babylon }\end{array}$ & $44^{\circ} 23^{\prime} 15.24^{\prime \prime}$ & $32^{\circ} 24^{\prime} 13.00^{\prime \prime}$ \\
\hline 2 & 1.5 & Governorate Center & $44^{\circ} 27^{\prime} 25.24^{\prime \prime}$ & $32^{\circ} 30^{\prime} 17.25^{\prime \prime}$ \\
\hline 3 & 2.5 & Al-Qasim subdistrict & $44^{\circ} 38^{\prime} 13.2^{\prime \prime}$ & $32^{\circ} 15^{\prime} 50.4^{\prime \prime}$ \\
\hline 4 & 3.25 & Al-Qasim subdistrict & $44^{\circ} 41^{\prime} 45.5994^{\prime \prime}$ & $\begin{array}{c}32^{\circ} 17^{\prime} \\
56.3994^{\prime \prime}\end{array}$ \\
\hline 5 & 4 & $\begin{array}{l}\text { Al-Hashimiyah } \\
\text { subdistrict }\end{array}$ & $44^{\circ} 39^{\prime} 39.6^{\prime \prime}$ & $32^{\circ} 21^{\prime} 43.2^{\prime \prime}$ \\
\hline
\end{tabular}




\subsection{Laboratory work}

The laboratory test was carried out on the five samples extracted from the holes by giving a dry particle size distribution using standard test methods for particle-size distribution of soil using sieve analysis (ASTM D6913 and D6913M - 17) to separate sand from silt and clay and wet test method by using standard test method for particle-size distribution of fine-grained soils using the sedimentation (hydrometer 151H) analysis (ASTM D7928 - 17) to separate the silt from the clay for each sample.

The laboratory work also involves determining the value of the maximum dry density of the soil by drawing the relation between the optimum moisture content and the dry density by using the standard test methods for laboratory compaction characteristics of soil using standard Proctor apparatus of finegrained soil in its standard mold (ASTM D698 -12e2). The last part of the laboratory tests is represented by using standard test methods for liquid limit (L.L.\%), plastic limit (P.L.\%), and plasticity index (P.I.\%) of soils "Atterberg Limits" (ASTM D4318-17e1). Atterberg limits are affected by the amount and nature of the clay minerals content in the soil, where plasticity is an important factor in determining the operability of clays or clay mixtures and their application to construction industries such as bricks, ceramics, and pottery, and it is also a good indicator of the phases of the main clay minerals in the soil, (Yongue et al., 2016 and Duggal, 2008).

\section{Results and Discussion}

The laboratory tests conducted on the five samples for the locations of the study area, (Table 2) showed that during the test of the particle size analysis and the atterberg limits, the class of the soil depending on unified soil classification system was CL Clay with low plasticity, except for the fourth and fifth sites, they classes were of the ML silty clay with low plasticity. The sand values ranged between 5- $38 \%$ and the silt between 18-27\%. As for the clay, its value ranged between 41-68\%. However, the percentage of Atterberg limits where the values of the liquidity limit ranged between $24-41 \%$ and the plasticity limit between $16-30 \%$. Thus, the values of the plasticity index ranged between $7-11 \%$, Where the activity of the soil gave all the studied samples an indication that it was of the inactive type, while the maximum dry density values ranged between $1.612-1.70 \mathrm{~g} / \mathrm{cm}^{3}$.

Table 2. Results of the physical properties of the studied samples

\begin{tabular}{ccccccccc}
\hline Sample & Sand\% & Silt \% & Clay\% & L.L.\% & P.L.\% & P.I.\% & USCS & $\begin{array}{c}\text { Dry Density } \\
\left(\mathbf{g} / \mathbf{c m}^{\mathbf{3}}\right)\end{array}$ \\
\hline 1 & 5 & 27 & 68 & 41 & 30 & 11 & CL & 1.612 \\
2 & 34 & 18 & 48 & 24 & 16 & 8 & CL & 1.651 \\
3 & 26 & 20 & 54 & 35 & 25 & 10 & CL & 1.701 \\
4 & 38 & 21 & 41 & 29 & 22 & 7 & ML & 1.680 \\
5 & 16 & 24 & 60 & 37 & 28 & 9 & ML & 1.632 \\
\hline
\end{tabular}

And when we analyze this data by the statistical matrix method and we use the Pearson correlation as shown in Table 3 for the purpose of reaching to clarify the relationship of the physical properties of the sample between them and the dry density, the correlation factor was extracted. We notice from the table that the values of the correlation coefficient range between negative and positive, and this indicates that there is an inverse correlation exchange with some physical properties and a direct correlation with some other. When observing the relationship between the percentage of sand in the sample and the Atterberg limits, we find that it is a negative inverse correlation. This means that the increase the percentage of sand, the decrease the percentage of the Atterberg limits. 
Table 3. Results of the correlation coefficient of dry density with the physical properties of the samples

\begin{tabular}{ccccccccc}
\hline & & Dry & Sand & Silt & Clay & L.L. & P.L. & P.I. \\
\hline \multirow{4}{*}{ Dry } & Pearson Correlation & 1 & 0.727 & -0.714 & -0.695 & -0.424 & -0.409 & -0.380 \\
& Sig.(1-tailed) & & 0.082 & 0.088 & 0.096 & 0.239 & 0.247 & 0.264 \\
& N & 5 & 5 & 5 & 5 & 5 & 5 & 5 \\
Sand & Pearson Correlation & 0.727 & 1 & $-0.888^{*}$ & $-0.988^{* *}$ & $-0.900^{*}$ & $-0.851^{*}$ & $-0.869^{*}$ \\
& Sig.(1-tailed) & 0.082 & & 0.22 & 0.001 & 0.019 & 0.034 & 0.028 \\
& N & 5 & 5 & 5 & 5 & 5 & 5 & 5 \\
Silt & Pearson Correlation & -0.714 & $-0.888^{*}$ & 1 & 0.805 & $0.883^{*}$ & $0.901^{*}$ & 0.626 \\
& Sig.(1-tailed) & 0.088 & 0.22 & & 0.050 & 0.023 & 0.018 & 0.129 \\
& N & 5 & 5 & 5 & 5 & 5 & 5 & 5 \\
Clay & Pearson Correlation & -0.695 & $-0.988^{* *}$ & 0.805 & 1 & $0.860^{*}$ & 0.791 & $0.908^{*}$ \\
& Sig.(1-tailed) & 0.096 & 0.001 & 0.050 & & 0.031 & 0.055 & 0.017 \\
& N & 5 & 5 & 5 & 5 & 5 & 5 & 5 \\
L.L. & Pearson Correlation & -0.424 & $-0.900^{*}$ & $0.883^{*}$ & $0.860^{*}$ & 1 & $0.987^{* *}$ & $0.823^{*}$ \\
& Sig.(1-tailed) & 0.239 & 0.019 & 0.023 & 0.031 & & 0.001 & 0.043 \\
& N & 5 & 5 & 5 & 5 & 5 & 5 & 5 \\
P.L. & Pearson Correlation & -0.409 & $-0.851^{*}$ & $0.901^{*}$ & 0.791 & $0.987^{* *}$ & 1 & 0.719 \\
& Sig.(1-tailed) & 0.247 & 0.034 & 0.018 & 0.055 & 0.001 & & 0.085 \\
P.I. & N & 5 & 5 & 5 & 5 & 5 & 5 & 5 \\
& Pearson Correlation & -0.380 & $-0.869^{*}$ & 0.626 & $0.908^{*}$ & $0.823^{*}$ & 0.719 & 1
\end{tabular}

* Correlation is significant at the 0.05 level (1-tailed).

** Correlation is significant at the 0.01 level (1-tailed).

By noting the relationship between the dry density and the percentage of sand in the sample, we find that it is a direct correlation, but when existing the quantities of silt and clay in the sample, we find that it is an inverse correlation with the values of dry density and their percentages. But on the other hand, we note that the correlation coefficient takes the positive value when the percentages of silt and clay increase, and this indicates the existence of a direct correlation between them and the Atterberg limits. There is a function value when it is less than or equal to 0.05 it is clear at the percentage of clay and their relationship with the plastic limit and the plasticity index. After conducting the required laboratory tests on the samples and knowing the ratio of their contents, properties and classification, it was possible to conduct a descriptive section for each station as shown in Fig. 2. The field description linking with the data of the results from engineering analyses of the soil and its properties and classification, it gives us an important and sensitive description of the studied soil section, and knowing the nature motion of sediments in the area in especially. To talk about soil activity, which is a reflection of the ratio of fine materials and clay, it also gives us a good indication of the presence or absence of clay minerals that affect the ability of clay soil to swelling. By good observation of the results listed in the (Table 4) which clearly describes soil samples and their effectiveness and connect it with what is clear in the Skmpton diagram (Fig .3) we note that it ranged between 0.15-0.19. By drawing the relation between the values of the particle size distribution characteristic in its three sizes and the values of the properties of plasticity index and the maximum dry density, which are considered one of the most influential physical properties in engineering applications where it was found that the percentage of clay affects the increase in plasticity (Fig.3). 


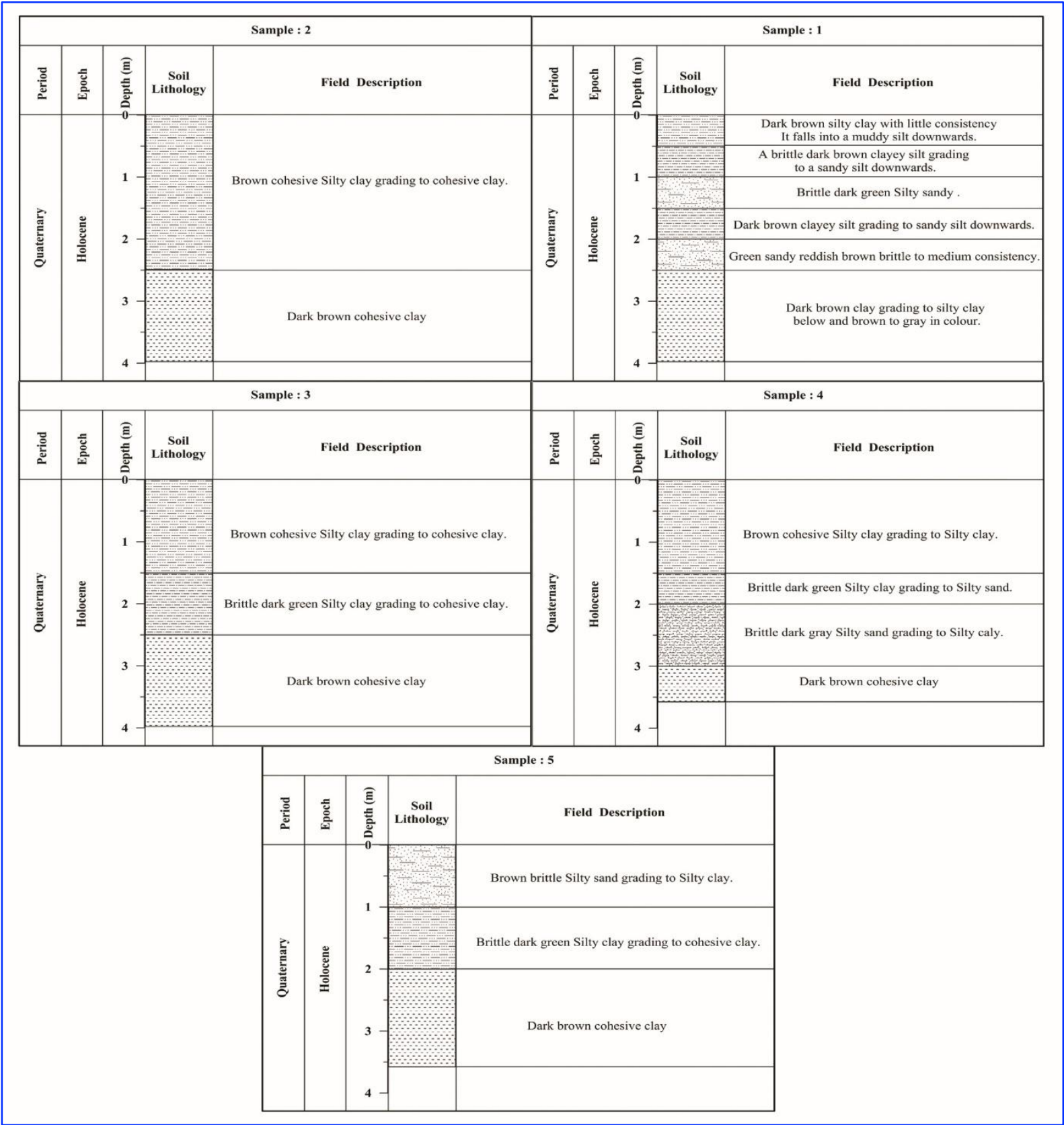

Fig. 2.Stratigraphic section of the studied stations

Table 4. Results of the activity of the studied samples, and the classification according to (Al-Waeli, 2018)

\begin{tabular}{ccccc}
\hline & Activity of soil samples & & \multicolumn{2}{c}{ Activity of soil (Al-Waeli,2018) } \\
\hline Sample & Value & Description & Value & Description \\
1 & 0.18 & Inactive & less than 0.75 & Inactive \\
2 & 0.17 & Inactive & $0.75-1.25$ & Normal \\
3 & 0.19 & Inactive & $1.25-2.00$ & Active \\
4 & 0.171 & Inactive & Less than 6 & Very active as \\
5 & 0.15 & Inactive & & montmorillonite \\
\hline
\end{tabular}




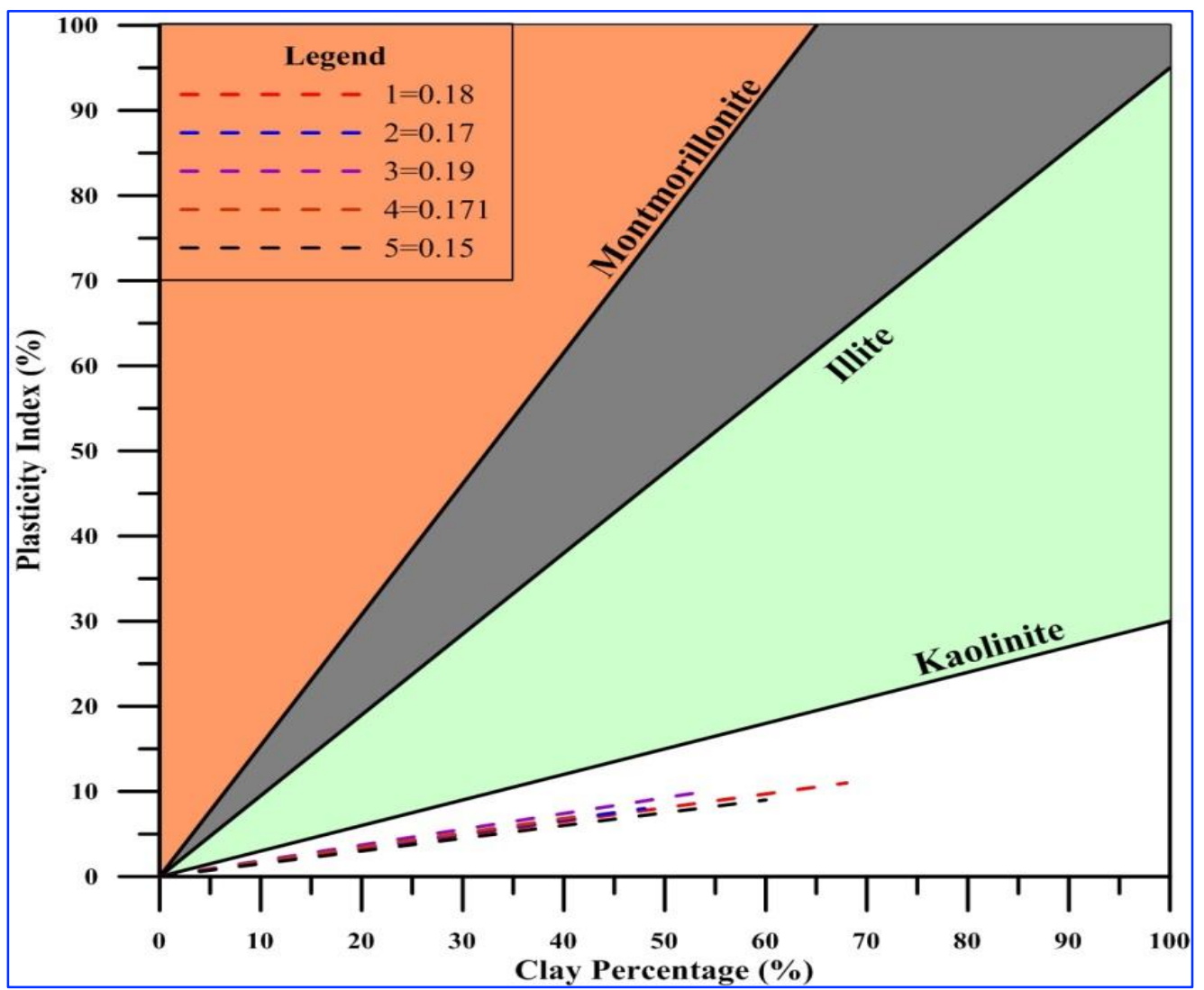

Fig. 3. Relationship between the ratio of fine materials to the plasticity index, (Skempton,1948)

Through the Skempton diagram, we clearly notice that the slope values of the lines for the study samples fall within the kaolinite range nearly. So, it is easy to say that these studied soils are not within the swelling soil range of the montmorillonite. For example, the diagram of the relationship between the proportions of sand, silt and clay with the plasticity index (Fig. 4), shows that the plasticity index decreases with the increase in the amount of sand in the sample.

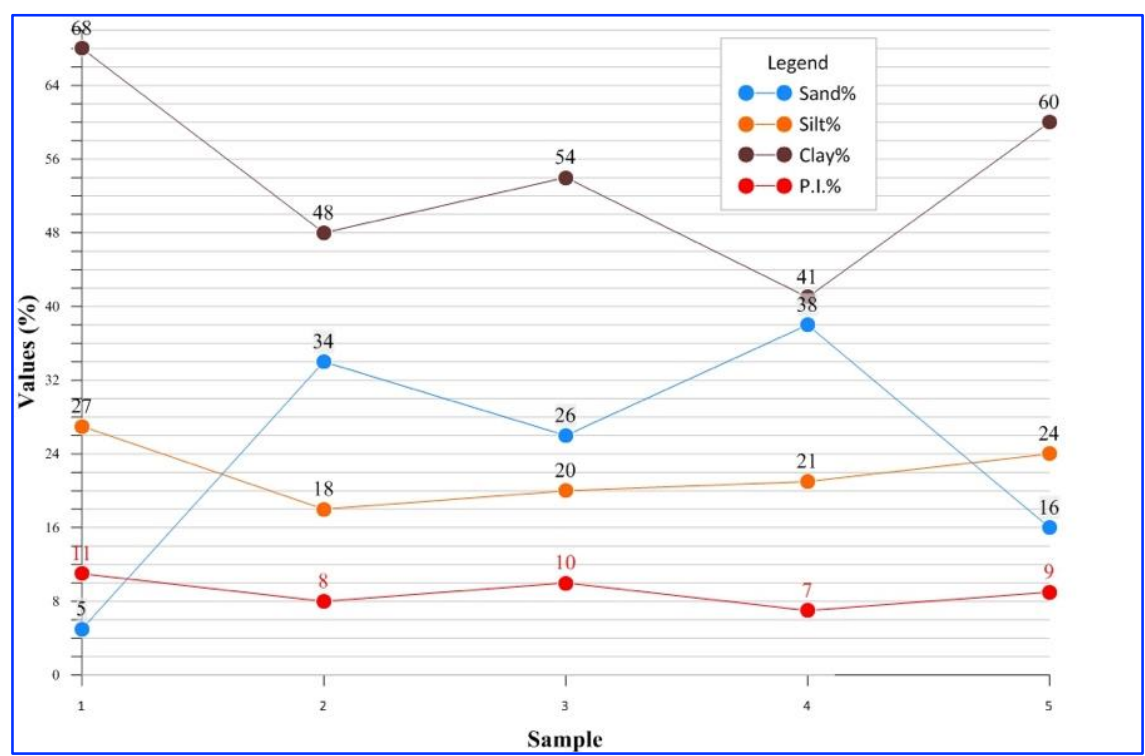

Fig. 4. Diagram showing the relation between the values of particle size distribution and the plasticity index ratio 
As for the curves of the liquid limit and plastic limit, they are approximately in line with the curvature of the presence of clay and opposite to the curvature of the presence of sand (Figs. 5 and 6).

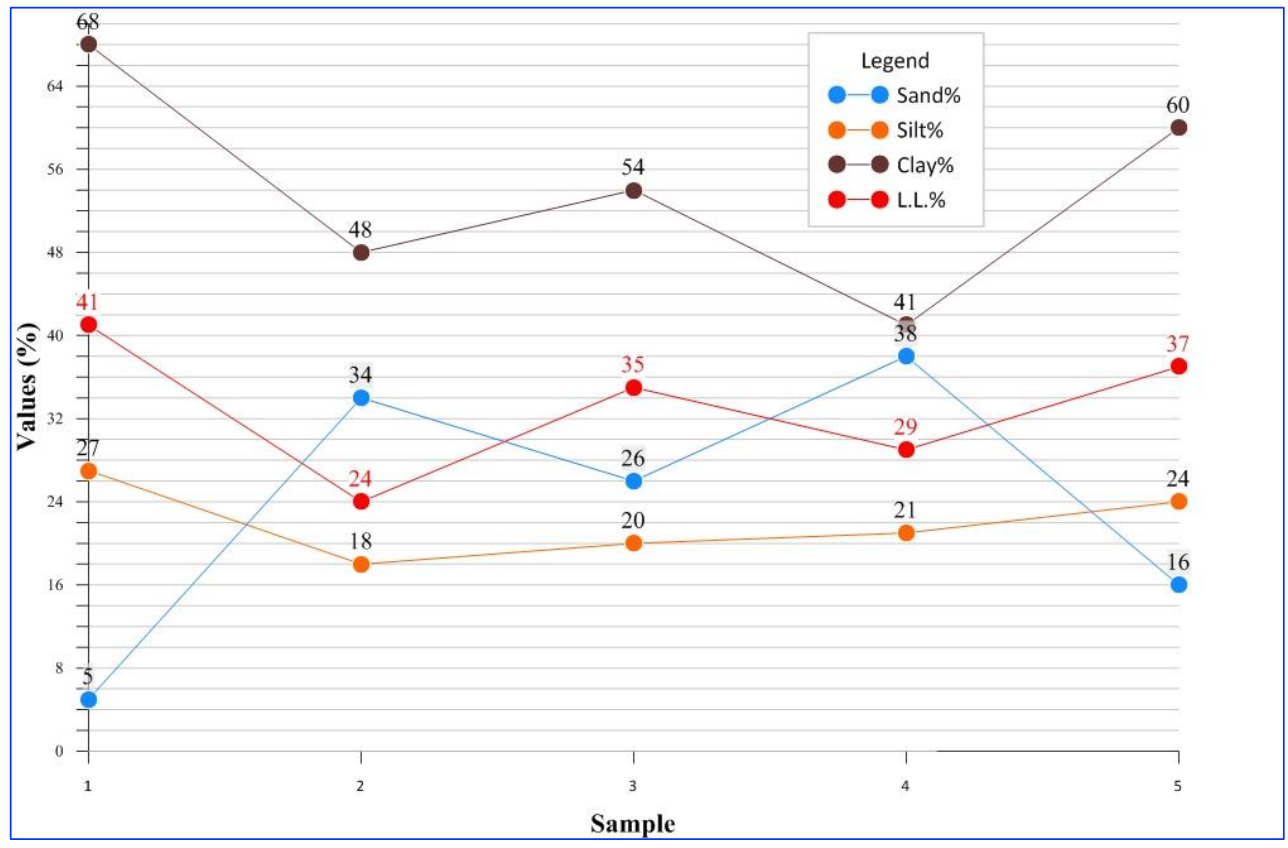

Fig. 5. The relation between the values of particle size distribution and the liquid limit ratio

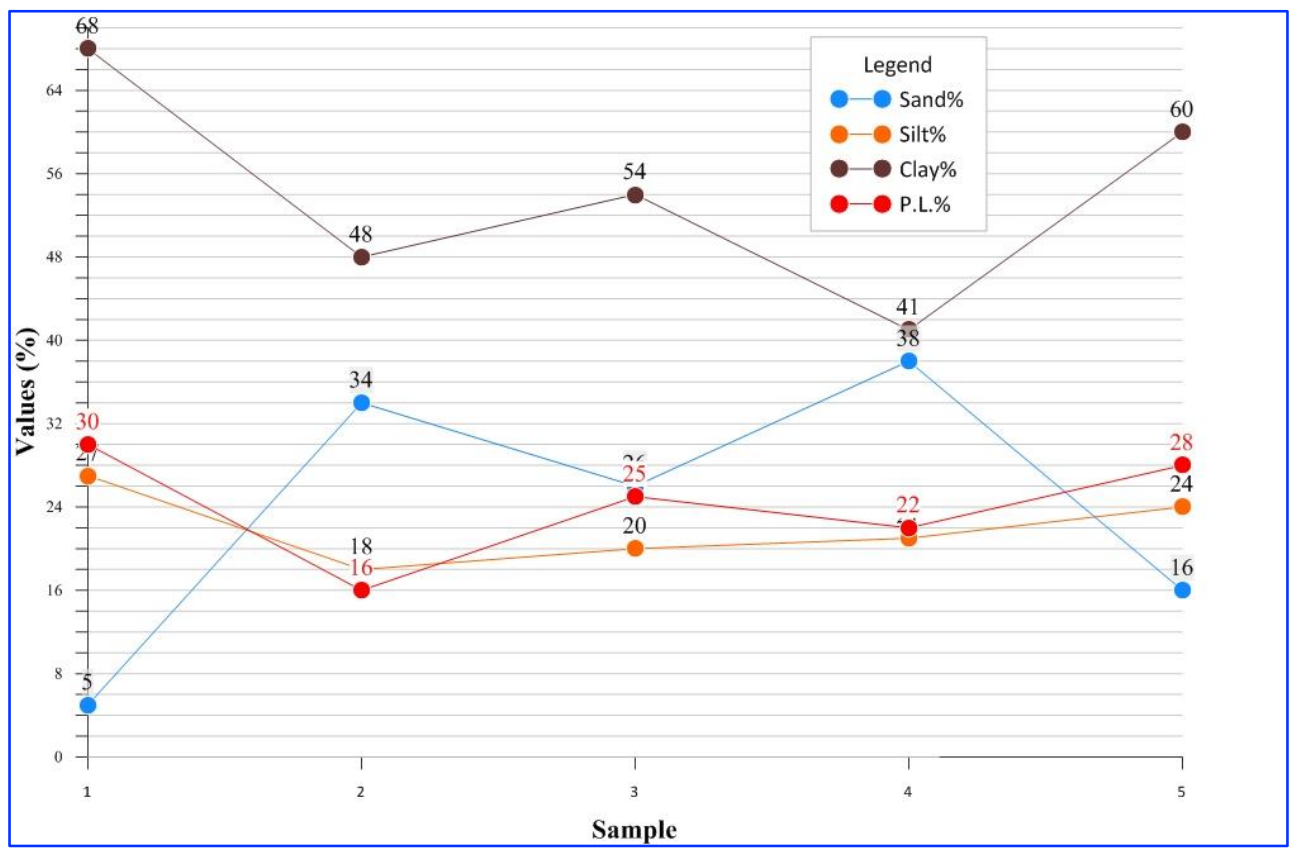

Fig. 6. The relation between the values of particle size distribution and the Plastic limit ratio

The maximum dry density is clearly affected by a significant increase with an increase in sand, offset by a decrease in fine materials to reach the highest value of $26 \%$ sand, then it begins to descend again (Fig.7). Thus, in order to obtain an appropriate compaction rate when erecting engineering facilities, it is necessary to take into account the percentage of sand presence in the soil prepared for filling under the foundations. 


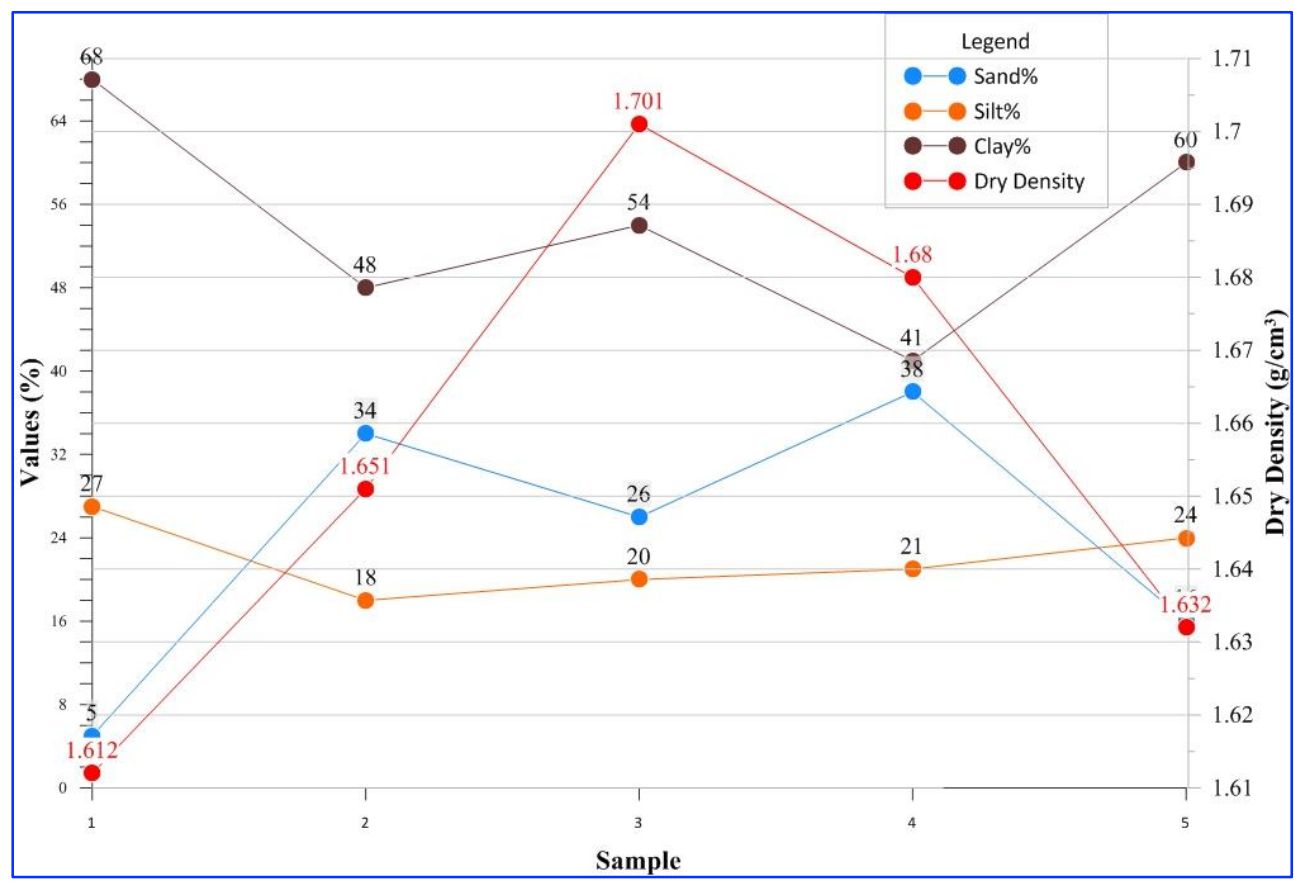

Fig. 7. The relation between the values of particle size distribution and the maximum dry density ratio

\section{Conclusions}

- The particle size distribution property is most influential in drawing other physical properties such as plasticity, maximum dry density and soil activity, and it is the basis of the relationship between the physical properties.

- For maximum dry density, there must be a suitable grain size distribution for the soil so that the percentage of sand does not exceed (20-30) \% and the remainder of the fine grains.

- Applications of engineering geology in the field of soil uses for construction and industrial purposes require investigations commensurate with the use and taking into consideration its physical properties, and it is a guide to other properties.

\section{Acknowledgements}

The authors would like to thank the Heads of the Department of Applied Geology at the Babylon University for permitting us to use the laboratories and laboratory equipment for physical and chemical tests. The authors are very grateful to the B.A. CAPTURE group for their great efforts in providing scientific services Such as maps, satellite images, graphics, ideas, and others. The authors are very grateful to the Editor in Chief Prof. Dr. Salih M. Awadh, the Secretary of Journal Mr. Samir R. Hijab. and the Technical Editors for their great efforts and valuable comments.

\section{References}

Al-Waeli, M. M., 2018. Basics of soil mechanics and its engineering applications. Baghdad and Jordan. Tigris Library, Al-Wadeh Publishing.

Abdulla, R., Majeed, N.,2021. Enhancing engineering properties of expansive soil using marble waste powder. Iraqi Geological Journal, 54 (1E), 43-53.

Al-Jeafir, M.L., Hussian, A. 2020. Sedimentological, mineralogical and environmental study of the euphrates river from Babylon to Basrah, Iraq. Ph. D. Thesis, university of Basrah, Basrah, Iraq 238 pp. 
Ajeet, K. K., 2015. Engineering materials. Khairpur College of Agricultural Engineering \& Technology, Constituent College of Sindh Agriculture University Tandojam.

Arthur, L., 2007. Materials for architects \& builders. 3ed edition ,383 pp.

ASTM D 6913 / D 6913, 17. Standard test methods for particle-size distribution (gradation) of soils using sieve analysis. Annual Book of ASTM Standards. American Society for Testing and Materials.

ASTM D 4318, 17. Standard test methods for liquid limit, plastic limit, and plasticity index of soils. Annual Book of ASTM Standards. American Society for Testing and Materials.

ASTM D7928, 17. Standard test method for particle-size distribution (gradation) of fine-grained soils using the sedimentation (hydrometer) analysis. Annual Book of ASTM Standards. American Society for Testing and Materials.

ASTM D 698, 12 .Standard test methods for laboratory compaction characteristics of soil using standard effort. Annual Book of ASTM Standards. American Society for Testing and Materials.

Braja, M., Das, K. S., 2018. principles of geotechnical engineering. Cengage Learning. Boston, 845 pp.

Duggal, S. K., 2008. Building Materials. New age international publishers, third revised edition, 52-83 pp.

Holtz, R.D., Kovacs, W.D., 1981. An introduction to geotechnical engineering prentice-hall, inc. New Jersey, NY, USA, 733 .

Jassim, S. Z., Goff, J. C., 2006. Geology of Iraq. First ed., Czech Requblic, 314pp.

Jawaid, M., Qaiss, A. el Kacem Rachid, B., Bouhfid, R., 2016. Nanoclay reinforced polymer composites nanocomposites and bionanocomposites. Laboratory of Biocomposite Technology, Universiti Putra Malaysia. Serdang Malaysia, 391pp.

Luan,V. N., Nu,N. T.,Toan,D., M., 2021.Consolidation properties of Ho Chi Minh City Soil, Vietnam.Iraqi Geological Journal, 54 (1A),1-10.

Mahendran, K., Vignesh, N.P., 2015. A study on the influence of soil properties and additives on the strength of mud blocks. International Journal of Applied Engineering Research, 10, 53.

Skempton, A.W., 1948. A possible relationship between true cohesion and the mineralogy of clays. Proc.eeding 2nd International Conference, 7, 45.

Yongue, F. R., Ndimukong, F., Njoya, A., Kunyukubundo, F., Mbih, P. K., 2016. Mineralogical, geochemical, physical characteristics and properties of their fired products. Journal Asian Ceramic Society, 4(3), 299308. 